\title{
Analyzing the Effects of Applying IoT to a Metal-Mechanical Company
}

\author{
Eduardo Cañizares iD, Faustino Alarcón Valero iD \\ Universitat Politècnica de València (Spain) \\ ecanyzares@yahoo.es,faualva@omp.upv.es
}

Received: November 2017

Accepted: February 2018

\begin{abstract}
:
Purpose: The purpose of this paper is to show the improvements obtained through the application of Io'T in a company of the metal-mechanical sector.

Design/methodology/approach: The methodology used has been the collection of data before and after the application of the IoT in the process to manufacture tool-machines.

Findings: Improvements obtained in some aspects of the process are very high (above 30\%), making it a process that is more efficient allowing reduce costs.

Research limitations/implications: Some aspects or details are difficult to quantify because there are no measurable parameters.

Practical implications: Technological advances and new technologies applied to the industry, allows significant improvements in production.

Social implications: Improvements obtained in the process can improve the conditions of workers.

Originality/value: Originality of the paper is very high, because there are not many publications of study or practical cases in this sector, due to the confidentiality and competitiveness of the sector.
\end{abstract}

Keywords: internet of things, industry 4.0, manufacturing, improvement, process, die, tooling, stamp, rfid, wi-fi

\section{Introduction}

Every day are growing up the devices that have sensors in their structure to have the ability to communicate. This phenomenon is changing and affecting all facets of our lives. The new information networks that result from these new technologies promise to create new business models, improve business processes and reduce costs and risks (Chuii, Löffler \&. Roberts, 2010). An example of all this is the study case of the application of IoT to animal ecology (Guo, Qiang, Luan, Xu, He, Yin et al., 2015). At medical sector, there are patients who are taken care from home, and in logistics, the traceability and temperature are followed by RFID technologies. These changes are going to produce a new technological world revolution that can be comparable to the effects that produced the industrial revolution at the past. We can see a planet 2.0 where the immediacy and automatisms, will be common in all society. The connection to the information networks of all types of devices can enable a multitude of applications depending on the sector where these technologies are applied.

At the industry, it begins to speak about industry 4.0 or factories 4.0. This term is coined by the fourth industrial revolution. Recently, we can find in the literature about IoT a lot of theory and technology, especially in sectors such as logistics and transportation, but there are not many articles in manufacturing environments that explain real and concrete situations. 
For these reasons the objectives of this paper are:

a) Analyze effects and results to apply IoT in a manufacturing company of the metal-mechanical sector.

b) Verify the benefits mentioned in the literature are obtained and quantify them.

c) Identify disadvantages and see if they are collected in the literature.

Therefore, the interest of this work is to provide a real example of application of IoT in a company, with the validation and quantification of the advantages and disadvantages named at literature and serve like an example for potential users or CEOs who want to apply to their companies.

The sections in which the work has been structured are the following; Section two shows the results of the state of the art obtained in reference to the most outstanding advantages and disadvantages of IoT are discussed below. Third section briefly describes the process performed in a metal-mechanical company and the improvement introduced through the IoT. Following two sections show the advantages obtained with their quantification and a comparison with the advantages found in the literature. Finally, the conclusions and future work are presented.

\section{State of the Art, Advantages and Disadvantages of IoT}

In the IoT literature, some of the advantages and disadvantages of application in different sectors of society are described (Soumyalatha, 2016; Bhayani, Patel \& Bhatt, 2016). This section is based on three papers, which are reviews covering many other works, citing the most important general advantages in the application of IoT and other more specific advantages in reference to the IoT applied to the production planning process (Alarcón , Perez \& Boza, 2016) highlighting the main benefits.

Figure 1 shows a summary table of the main general advantages and disadvantages of the IoT from the literature

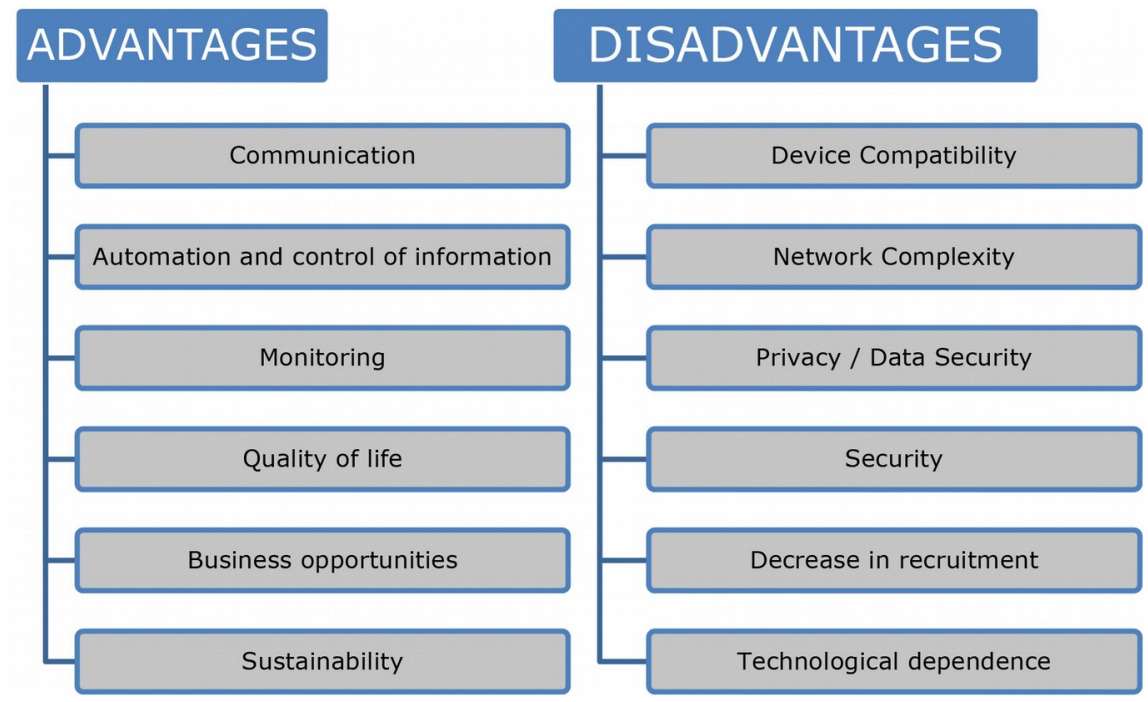

Figure 1. Advantages and disadvantages of Io'T (Soumyalatha, 2016)

Main general advantages cited by the authors are:

- Communication improvement which is more fluent, reducing transmission time.

- Increased automation and control of process information through RFID and Wi-Fi technology.

- Better knowledge of the data by being able to be monitored with intelligent sensors, saving time and money.

- Worker health improvement by reducing stress and facilitating tasks.

- Increased work capacity by better managing the workload of the company.

- Increased sustainability by reducing the use of paper and the use of resources necessary for production. 
Other authors such as (Alarcón et al., 2016), after reviewing the literature about the IoT applied to the process of production planning, consider some more concrete and defined advantages:

- Bigger efficiency of system and production in general, according to the needs of the customer.

- Higher quality and safety in the traceability of products through IoT.

- Facility of integration through the exchange of information between supply chain stakeholders.

- Reduced costs by improving management, reducing inventory levels, checking defects, increasing system efficiency, reducing errors and less dependence from operators.

- Improved customer response with more reliable deliveries, increased service level, demand changes detection and adjustments needed to meet demand.

Some of the disadvantages that the different authors (Soumyalatha, 2016; Bhayani et al., 2016) comment on are:

- Poor compatibility of devices from different manufacturers for an inexistent international standard.

- Increased network complexity where any software, hardware or power failure has serious consequences.

- Decreased privacy / security of data monitored by companies and transmitted through smart sensors and different technologies.

- Decrease in the recruitment of personnel for the daily tasks automation that produces less human intervention.

- Higher dependence on the technology that controls the routine of our lives.

After reviewing the literature and in view of the articles found, it can conclude that it is not easy to find papers or documents of study cases about application of IoT in the metal-mechanic sector. This paper shows the improvements obtained through the IoT by a tool-machines manufacturing company, being a specific case study within the sector.

\section{IoT Application in a Metal-Mechanic Company}

At this context, the company is an SME (Small and medium-sized Enterprise) which manufactures tool-machines and molds. There are nine sections with a total of fifteen different types of machines to work metals and steels to get pieces and components for each tooling machine project. The company has a wide range of customers from several sectors, like aeronautic, automotive, plumbing, services, etc. The company has used IoT to improve the production process of tool-machines, using RFID technologies and wireless networks, monitoring and managing the data about manufacturing status from each component and workload from each factory section and each machine. This is possible defining KPIs that monitoring the process in order to be able to show the manufacturing states from each component and the load states from each section, giving much more accurate information.

A tool-machine is a device that is mounted on a press (mechanical, pneumatic, etc.) that apply a force on the elements of the tool-machine, causing the upper part to fit on the lower one or matrix. This tool-machine produces the stamping of the material that has been interposed between both parts. Tool-machines can perform different operations: cutting, perforating, stamping, bending, or forming (Navarro, 1958).

Process to make a stamping tool-machine is quite complex because the large number of sub-processes (about 34 sub-processes and activities) that make it up. Be able to apply new IoT technologies to manage it in a more efficient way, it can produce a great competitive advantage (Cañizares, 2016).

Components that take part in a tool-machine can be grouped into three subsets, upper, intermediate and lower, which are structured according to the assembly of all the components (Cañizares, 2016).

Sub-processes that are performed are also divided into previous activities, manufacturing sub-processes and assembly sub-process. In the previous activities, the design is analysed and realized, through the preparation of previous sketches and subsequent realization of plans and process sheets of each component (Cañizares, 2016). 
Follow up of each manufacturing sub-process of each of the components causes a lot of errors in the management and production of each tool-machine, with the consequent delay that it means. The manufacturing technology is advanced and cannot get important process improvements, but the IoT application offers an opportunity to improve the management, control and monitoring of the different sub-processes, as well as to know the load state of work of the different factory sections.

Defining all necessary KPI's (Key Performance Indicators) and the application of existing technologies such as RFID and Wi-Fi, it is possible to transmit the information of the sub-processes and tasks, as well as the workload of the different factory sections.

The main objective of the application of the IoT in the company is the improvement of the tool-machines making process. The improvement processes methodology chose to apply at this company it was AS-IS/TO-BE methodology. In the first phase, the process was described. In the second phase, it was analysed and detected the problems, inefficiencies and improvable aspects. In the last phase, the process was remodelled with the improvements introduced.

The improvements of the process of elaboration of matrices through the application of the IoT, are get with the installation of different IoT devices. Each tool-machine component carries a RFID tag which let the component is identified in the system and its traceability and manufacturing status can be followed. In each section (machines and workstations) there are RFID code reading guns which are used to identify the component when it arrives. When each of the tasks that it must be completed is finished, the RFID code of the component is read again to change the value of the parameter assigned to that task and then, the percentage of completion in which the component is found is modified.

All these data entered in the system allow knowing the manufacturing state of each component, the workload of each machine, the workload of each section, etc. Some parameters change their value directly through the action of reading the RFID code of the component and modifying its value at the end of the task. Other parameters show a value that is obtained by calculating with other parameters to show the percentage of total realization status of the tool-machine or the workload of a section of the company.

The data are monitored through devices connected to the internet through a Wi-Fi network. It can be accessed from computers, tablets or smart phones through an application which let shows all the data obtained from the components parameters.

For each activity and sub-process that take part in a tool-machine elaboration process, it was necessary to define the objectives and parameters in a right form. Each objective has associated parameters, and these parameters indicate the status of each task through its modification once the task is done.

The list of objectives and parameters is very extensive because there are many sub-processes and activities (over 34 sub-processes and activities) in the development of a tool-machine. All of them have associated a number of parameters according to the different tasks defined for each component. The total list of parameters is also very high, reaching 101 in this study case (depending on the different tool-machine model, the number of parameters are not the same, could be higher or lower).

Each manufactured tool-machine is different, so in the planning phase of its elaboration, the objectives and parameters are defined, which are usually similar but with variations according to the differences between the manufactured tool-machines.

The system does not provide manufacturing data in real time, because that requires a uniform data-reading interval over time. The readings are made when the tasks assigned to each component are finished. At the end of each working day a final reading is made to adjust the data system to reality to start the next day with right production data. 


\section{Advantages Obtained and Quantification}

Application of the IoT to the process produces an adaptation and transformation that entails general and other more particular advantages to the concrete case which is being analyzed.

Main advantage of applying the IoT to the improvement of the manufacturing process of a tool-machine is to be able to know in real time (approximate), the state of the overall process, the state of processing of its components and the workload of each factory section.

The KPI's formulas used to measure the improvement, in general show the subtraction between value before IoT implementation and value get it with IoT technologies implemented to control the process of elaboration of tool-machines.

$$
\% \text { Improvement }=\% X_{n}-\% X_{n-1}
$$

Where $\% X_{n}$ is the value after IoT use, $\% X_{n-1}$ is the value before IoT use.

For advantage, $\mathrm{A} 2$ it is take the subtraction of sub-processes controlled, divided by total number of sub-processes:

$$
\text { KPI A2 }=(34 \text { sub-pr. }-13 \text { sub-pr. } / 34 \text { sub-pr. }) \times 100=61.8 \%
$$

For advantage, A3 it is take the number of monitored sub- processes before and after Io'T application.

$$
\text { KPI A3 = (32 sub-pr. } / 34 \text { sub-pr. }-13 \text { sub-pr. } / 34 \text { sub-pr. }) \times 100=55.9 \%
$$

Other KPI's are calculated in an analogous way.

All this improves communication and makes it flow through the system, which helps to solve problems that are presented in a faster and more effective way. The method of information transmission between the different sections and between the different sub-processes, was being done through paper work orders that was filled by the workers of each workstation to know the information about tasks status level and was filled by section managers to know the information about of workload status. The average time of information transmission, that was obtained (average global factory value) after all measurements made at previous analysis work, showed around 25 minutes. Estimated improvement communication makes information more fluid between different sections within the company and between different sub-processes, reducing the transmission time from 25 minutes to 7.5 minutes on average. This means a reduction of $30 \%$ of the time used.

Implementation of the IoT has produced an increase in automation of processes and an increase in the control of information, from being automated 13 sub-processes to being automated and controlled the 34 sub-processes, which means an increase of $61.8 \%$. The installation of RFID systems at sections for reading the information of each component, prevents the worker from having to waste time writing work orders as they did before applying IoT, this increase the control speed. It means an automation of the process that produces improvements of time and reduces the mistakes through a better control. Furthermore, it helps to plan and distribute better the tasks between the different machines, reducing the workload.

This allows knowing the workload of each factory section with great precision, avoiding work overloads and allows getting better organization of the sub-processes of each item. The company before it had an estimate of the workload performed by each section manager. New system introduces the work orders of each sub-process and each component through computers and interconnected devices to the system, offering information instantly and without being lost the component.

The application controls all the information of the process, which has allowed a better knowledge of the data when it is monitored practically in real time, using intelligent sensors in 32 sub-processes of the 34. Before IoT application, company only get data from 13 sub-processes of the 34. This represent an increment of $55.9 \%$ of monitored processes with better data knowledge from them, this improves the decision-making by 
the company strategic direction that let save time and money. At the past, it was very difficult to know the state of the sub-processes, because the operators carried the work orders (in paper) between the different sections.

Application of the IoT to the whole production process allows an improvement in the quality of management, has an impact on the workers in key positions, reducing reported cases of stress from 7 to 3 workers. This improvement is an estimate of $42.9 \%$, because it is much more complex to quantify it.

Capacity of the factory increases with the reduction of the workload produced by the better management of the processes when implementing the IoT. This workload is reduced from $95 \%$ to $70 \%$, which represents a factory capacity increment around of $25 \%$.

Manufacturing process is more sustainable by reducing the use of paper and ink, resources used in work orders and some documents that has now been replaced by the use of stickers, QR codes and coding guns. This reduction in the use of paper and ink is estimated to be around $60 \%$ and make more responsible and respectable with the environment. There are other savings like in energy through reducing of production times and manufacturing mistakes, but it is necessary a longer time observation period to quantify it in a reliable way.

Some of the specific advantages achieved with the application of the IoT in the present study case, can be aligned with some of the benefits cited by (Alarcón et al., 2016) when the IoT is applied in the production planning process. Its article highlights between these benefits: greater efficiency, increase in quality and security, ease of integration (exchange of information), reduction of costs and improvement of customer response (sections can be considered as internal customers). Below are the specific advantages get in the tool-machines production process study case:

The use of the IoT produces an improvement of the decision-making when knowing the workload of each section. This improvement is very difficult to quantify, given the complexity of the number of decision-making that are taken in the different sections and by the different managers.

An exclusive advantage of this study case is the improvement in the distribution of the workload of the different factory sections. This improvement is the consequence of the most accurate and available information to be consulted through the internet at any time. This helps to improve the decision-making process.

This lets a rapid resolution of problems and conflicts during the production, reducing resolution time from 30 to 10 minutes, of average about 20 minutes of reduction. The application of the Io $\mathrm{T}$ in the process improvement allows the modification of the work plan according to the customers' needs. This time reduction means an improvement about 33,3\% in the resolution of problems. Sensors allows detect problems instantly and manage them before than in the past.

IoT reduces production time of each tool-machine project about a $15 \%$ because everything is controlled and monitored, all the sub-processes finish before and this affects to the global time. The process of making a tool-machine is quite long and complex and is composed of many production times of the manufacture of each component. The reduction obtained is produced by the better distribution of workloads, reduction of nonproductive times, reduction of errors, etc. in each of the tasks and machines. The total sum of all those small waste of time in a large number of sub-processes and tasks, results in a significant improvement in each tool-machine manufactured.

The efficiency of the process is greater when achieving the goals set for each sub-process and section in a shorter time and with a better management of resources. This improvement it was calculated in all the jobs and machines of the factory applying the formula of OEE (Overall Equipment Effectiveness) (Ljungberg, 1998) before the application of the IoT and after its implementation. The difference between averages of all OEE calculated before implementation and later, gives an improvement around 15\%.

Quality and safety monitoring of each component is increased through a higher control of the information sent from each section, which allows knowing the status of each component and its location at the factory. In order to 
perform a measurement of the traceability efficiency, it was made a test, which consisted of obtaining the information of the manufacturing status and the location of different components of the tool-machine in a determinated time. The test was made several times before and after the implementation of the IoT devices. The results obtained show similar values between the different components. It was obtained the information from the $75 \%$ of the components before the time set for the test. Carried out the test with the new technologies installed, the percentage increased until $90 \%$, which represents an increase of $15 \%$.

The process improvement through the applying the IoT makes it more efficient, reducing the total production time of each tooling about $15 \%$. This affects to the final customer's economic cost, which it is reduced. This it means the possibility of accepting other jobs and orders, which improves the service level about at least 15\%, compared to the process before being improved.

The customers and suppliers of the internal supply chain, are the same sections of the factory. The application of the IoT makes it easier to interrelate between the members of the internal supply chain. It was made a survey to measure this improvement. The managers and operators of each section answered questions about the tasks performed in the components in other sections different from theirs. This indicator reflects approximate data, because it depends on the perception of each worker. With the application of IoT technologies the information is more accessible than with paper work orders in the past and the results obtained from the surveys of this value about cross-section interaction improved around 20\% (from 5\% to 25\%).

Each small improvement achieved in each sub-process, having a high number of sub-processes, produces an important improvement that results in a $15 \%$ of reduction in overall cost.

The finished product is delivered to the final customer within the agreed term, giving reliability to the company. Economic cost is lower, which can be decisive when entering a competition to obtain new products to be made against other competitors. Reliability of on-time deliveries have increased by more than $15 \%$, reaching $95 \%$.

\section{Comparison of Advantages}

Many of the advantages of IoT application found throughout scientific literacy are reflected, in the study case showed at this paper, where it is analysed and studied the implementation of these new technologies in the industrial sector where are growing up their use although the complexity that it takes at this case.

Solution proposed applying the Io $\mathrm{T}$ in this paper, presents all the advantages found in the bibliographic review. Some of them are outstanding, make the process more efficient, and can be quantified or scaled as soon as they improve it (Cañizares, 2016).

In Table 1, the two columns on the right side show the advantages, which are present in the case study, and their concordance with those was found in the bibliographic review carried out previously.

There are two columns with the values of each advantage before applying IoT and value obtained later. This allows it can be appreciate the improvement percentage of each one of them that is showed it in the next column.

It is observed that there are three advantages (A8, A9 and A10) that are specific to the present case study and others that are much more general. It is easier to improve general advantages than specific.

Advantages that stand out most to get the best results (over 30\% or more) as shown in Table 1 are the following: A1, A2, A3, A4, A6 and A8, which correspond to communication, automation and control, monitoring, sustainability and reduction of time resolution problems. 


\begin{tabular}{|c|c|c|c|c|c|c|c|}
\hline Advantages & Description of advantage & $\begin{array}{l}\text { Value } \\
\text { before }\end{array}$ & $\begin{array}{l}\text { Value } \\
\text { after }\end{array}$ & $\begin{array}{l}\% \text { of } \\
\text { improvement }\end{array}$ & $\begin{array}{l}\text { State } \\
\text { of the } \\
\text { art }\end{array}$ & $\begin{array}{l}\text { Study } \\
\text { case }\end{array}$ & $\begin{array}{l}\text { Literature } \\
\text { reference }\end{array}$ \\
\hline \multicolumn{8}{|c|}{ General } \\
\hline A1 & $\begin{array}{l}\text { Improved communication by being } \\
\text { more fluid the information in each } \\
\text { section and sub-process. Reduced } \\
\text { transmission time. }\end{array}$ & $25 \mathrm{~min}$. & $7,5 \mathrm{~min}$ & $30 \%$ & $\mathrm{X}$ & $\mathrm{X}$ & $\begin{array}{l}\text { (Soumyalat } \\
\text { ha, 2016; } \\
\text { Bhayani et } \\
\text { al., 2016) }\end{array}$ \\
\hline A2 & $\begin{array}{l}\text { Increased automation of threads and } \\
\text { increased control of information. }\end{array}$ & $\begin{array}{c}13 \\
\text { subproc. }\end{array}$ & $\begin{array}{c}34 \\
\text { subproc. }\end{array}$ & $61,8 \%$ & $\mathrm{X}$ & $\mathrm{X}$ & $\begin{array}{l}\text { (Soumyalat } \\
\text { ha, 2016; } \\
\text { Bhayani et } \\
\text { al., 2016) }\end{array}$ \\
\hline A3 & $\begin{array}{l}\text { Better knowledge of the data } \\
\text { allowing its monitoring. }\end{array}$ & $\begin{array}{c}13 \\
\text { subproc. }\end{array}$ & $\begin{array}{c}32 \\
\text { subproc. }\end{array}$ & $55,9 \%$ & $\mathrm{X}$ & $\mathrm{X}$ & $\begin{array}{l}\text { (Soumyalat } \\
\text { ha, 2016) }\end{array}$ \\
\hline A4 & $\begin{array}{l}\text { Improvement of workers' } \\
\text { occupational health by reducing } \\
\text { stress. }\end{array}$ & $\begin{array}{c}7 \\
\text { workers }\end{array}$ & $\begin{array}{c}3 \\
\text { workers }\end{array}$ & $42,9 \%$ & $\mathrm{X}$ & $\mathrm{X}$ & $\begin{array}{l}\text { (Soumyalat } \\
\text { ha, 2016) }\end{array}$ \\
\hline A5 & $\begin{array}{l}\text { Increased work capacity of the } \\
\text { factory by reducing the workload. }\end{array}$ & $95 \%$ & $70 \%$ & $25 \%$ & $\mathrm{X}$ & $\mathrm{X}$ & $\begin{array}{l}\text { (Soumyalat } \\
\text { ha, 2016) }\end{array}$ \\
\hline A6 & $\begin{array}{l}\text { Increased sustainability of the } \\
\text { process by reducing paper and } \\
\text { resource use. }\end{array}$ & $100 \%$ & $40 \%$ & $60 \%$ & $\mathrm{X}$ & $\mathrm{X}$ & $\begin{array}{l}\text { (Soumyalat } \\
\text { ha, 2016) }\end{array}$ \\
\hline \multicolumn{8}{|c|}{ Specific to the planning process } \\
\hline A7 & $\begin{array}{l}\text { Improved decision making as the } \\
\text { workload of each section is known. }\end{array}$ & $\mathrm{n} / \mathrm{d}$ & $\mathrm{n} / \mathrm{d}$ & $?$ & $\mathrm{X}$ & $\mathrm{X}$ & $\begin{array}{l}\text { (Alarcón et } \\
\text { al., 2016) }\end{array}$ \\
\hline A8 & $\begin{array}{l}\text { Reduction of the time of resolution } \\
\text { of production problems by } \\
\text { modifying the work plan according } \\
\text { to the needs. }\end{array}$ & $30 \mathrm{~min}$ & $10 \min$ & $33,3 \%$ & & $\mathrm{X}$ & \\
\hline A9 & $\begin{array}{l}\text { Reduction of total production time } \\
\text { for each tool-machine. }\end{array}$ & $100 \%$ & $85 \%$ & $15 \%$ & & $\mathrm{X}$ & \\
\hline A10 & $\begin{array}{l}\text { Increase the efficiency of the system } \\
\text { by achieving the goals that are } \\
\text { marked for each sub-process. }\end{array}$ & $75 \%$ & $90 \%$ & $15 \%$ & & $\mathrm{X}$ & \\
\hline A11 & $\begin{array}{c}\text { Higher quality and safety in the } \\
\text { traceability of components and } \\
\text { products. }\end{array}$ & $75 \%$ & $90 \%$ & $15 \%$ & $\mathrm{X}$ & $\mathrm{X}$ & $\begin{array}{l}\text { (Alarcón et } \\
\text { al., 2016) }\end{array}$ \\
\hline A12 & $\begin{array}{l}\text { Increased ease of integration among } \\
\text { members of the internal supply } \\
\text { chain by improving cross-section } \\
\text { interaction. }\end{array}$ & $5 \%$ & $25 \%$ & $20 \%$ & $\mathrm{X}$ & $\mathrm{X}$ & $\begin{array}{l}\text { (Alarcón et } \\
\text { al., 2016) }\end{array}$ \\
\hline A13 & $\begin{array}{l}\text { Reduction of costs, through } \\
\text { reduction of inventory, control of } \\
\text { defects, greater efficiency, reduction } \\
\text { of errors and less dependence of } \\
\text { operators. The sum of } \\
\text { improvements in each section results } \\
\text { in a notable overall reduction in } \\
\text { costs. }\end{array}$ & $100 \%$ & $85 \%$ & $15 \%$ & $\mathrm{X}$ & $\mathrm{X}$ & $\begin{array}{l}\text { (Alarcón et } \\
\text { al., 2016) }\end{array}$ \\
\hline A14 & $\begin{array}{l}\text { Improved customer response, with } \\
\text { more reliable deliveries and increased } \\
\text { service level, detection of changes in } \\
\text { demand and adjustments. }\end{array}$ & $80 \%$ & $95 \%$ & $15 \%$ & $\mathrm{X}$ & $\mathrm{X}$ & $\begin{array}{l}\text { (Alarcón et } \\
\text { al., 2016) }\end{array}$ \\
\hline
\end{tabular}

Table 1. General and specific advantages of the IoT in the case study 


\section{Conclusions}

It is evident that the IoT is changing the habits of society in an evident way. There are many examples of this in different sectors, for example at home with sensors and processors you can automate the control of windows, home temperature, lights, etc., and connecting to the Internet can be controlled wirelessly through of a device (smart phone, tablet). In another area such as traffic safety, vehicles are incorporating sensors that allow modify the speed and be reduced when they are too close to another vehicle. These sensors connected to the internet, can send information to know the density of traffic and act on traffic lights to reduce the level of traffic in an effectively way.

IoT is a trend that is booming but most of what is written is almost all theoretical and there are few practical cases of application in industrial environments.

This study case presented shows the advantages obtained with the elaboration stamping tool-machines process' improvement through the application that facilitates the management and control of the information of the process with IoT.

This process improvement means a competitive advantage that can make a big difference over competitors, in a highly competitive market and where there is very little technological difference in the sub-processes themselves.

It is for this reason where significant improvements can be obtained, it is in the management of the information through the IoT as corroborated the data obtained.

This project was planned in several phases for its development. The implementation phase begins with the use of the application from a PC (Personal Computer), to detect errors and possible improvements. This phase is an experimental phase where the application is very basic (it has no developed graphics).

RFID devices and wireless technology are installed in the different sections of the factory. The application with which all the received information is controlled and allows to make variations on the sub-processes based on the data obtained, has been programmed to be used from a PC at this experimental phase.

The next phase consists in the programming and development of the application to use it from devices such as smart phones or tablets (devices that use different programming languages such as android). In this phase, the application must be completed with a more rigorous data collection to quantify all the improvements obtained in economic figures or graphics that show the collected data in a more visual and comfortable way for the user. This phase is responsible for the refinement and implementation at all levels. It is also necessary to take into account the security part for the restriction of access to the modification of the data depending on the type of user (company manager, section manager, worker, etc.).

Potential of the IoT is very great if it is applied in the companies in a suitable way. It is beginning to be implemented in companies and will soon be reflected in publications documenting practical implementation cases.

The scientific literature does not show many study cases published in the industrial sector, perhaps because of the high competitiveness that exists between companies. It would be interesting if other companies publish the data on the improvements obtained when applying IoT.

\section{Declaration of Conflicting Interests}

The author declared no potential conflicts of interest with respect to the research, authorship, and/or publication of this article.

\section{Funding}

The author received no financial support for the research, authorship, and/or publication of this article. 


\section{References}

Alarcón, F., Perez, D., \& Boza, A. (2016). Using the internet of things in a production planning context. Brazilian Journal of Operations \& Production Management, 13(1), 72-76. https://doi.org/10.14488/BJOPM.2016.v13.n1.a8

Bhayani, M., Patel, M., \& Bhatt, C. (2016). Internet of Things (IoT): In a Way of Smart World. In Proceedings of the International Congress on Information and Communication Technology (343-350). Springer, Singapore.

Cañizares, E. (2016). Mejora del proceso de elaboración de una matriz. progresiva de estampa-ción mediante el uso del Internet de las Cosas (IoT). TFM, ETSII-Universidad Politécnica de Valencia.

Chui, M., Löffler, M., \&. Roberts, R. (2010). The internet of things. McKinsey Quarterly, 2(2010), 1-9.

Guo, S., Qiang, M., Luan, X., Xu, P., He, G., Yin, X. et al. (2015). The application of the Internet of Things to animal ecology. Integrative zoology,10(6), 572-578. https://doi.org/10.1111/1749-4877.12162

Ljungberg, O. (1998). Measurement of overall equipment effectiveness as a basis for TPM activities. International Journal of Operations \& Production Management, 18(5), 495-507. https://doi.org/10.1108/01443579810206334

Navarro, T.L. (1958). Troquelado y estampado (5 $5^{\mathrm{a}}$ ed.). Barcelona: Gustavo Gill, S.A.

Soumyalatha, S.G.H. (2016). Study of IoT: Understanding IoT Architecture, Applications, Is-sues and Challenges. 1st International Conference on Innovations in Computing \& Net-working (ICICN16), CSE, RRCE. International Journal of Advanced Networking \& Applications.

Journal of Industrial Engineering and Management, 2018 (www.jiem.org)

\section{(c) (i) (\$)}

Article's contents are provided on an Attribution-Non Commercial 4.0 Creative commons International License. Readers are allowed to copy, distribute and communicate article's contents, provided the author's and Journal of Industrial Engineering and Management's names are included. It must not be used for commercial purposes. To see the complete license contents, please visit https://creativecommons.org/licenses/by-nc/4.0/. 